\title{
Vaginal infections among pregnant women at Omdurman Maternity Hospital in Khartoum, Sudan
}

\author{
Zeinab A. Abdelaziz ${ }^{1}$, Mutasim E. Ibrahim¹ ${ }^{1}$ Naser E. Bilal ${ }^{1}$, Mohamed E. Hamid ${ }^{2}$ \\ ${ }^{1}$ Department of Medical Microbiology, Faculty of Medical Laboratory Sciences, Khartoum University, Sudan \\ ${ }^{2}$ Department of Clinical Microbiology and Parasitology, College of Medicine, King Khalid University, Abha, Kingdom \\ of Saudi Arabia
}

\begin{abstract}
Introduction: Microbial infections of the vagina in pregnant women are health problems that lead to serious medical complications and consequences. This study aimed to investigate and determine antimicrobial susceptibilities of the causative agents of vaginal infections in pregnant women.

Methodology: A cross-sectional study of pregnant women $(n=200)$ was conducted between August and December 2008 at Omdurman Maternity Hospital, Khartoum, Sudan. Vaginal and cervical swabs were obtained from each subject and processed for isolation and identification of pathogenic microorganisms using standard methods of wet mount preparation, direct Gram smear, Nugent scoring system, direct immunofluorescence, and cultural techniques. Antimicrobial susceptibility testing of bacterial isolates was performed using standard procedures. Statistical analysis was done using SPSS program version 12.0.1. A p value $<0.05$ was considered statistically significant.

Results: Of the 200 pregnant women enrolled, BV was detected in $49.8 \%$, followed by Chlamydia trachomatis (31.3\%) and Candida albicans (16.6\%), with low frequencies of Neisseria gonorrhoeae (1.8\%) and Trichomonas vaginalis $(0.5 \%)$. Higher infection rates were recorded among subjects in the third trimester $(71.6 \%)$ than in the second trimester of gestation $(28.4 \%)$. No significant association $(\mathrm{p}=0.7)$ between history of abortions and C. trachomatis infections was found. Gentamicin was the most active agent against Gram-positive and Gram-negative bacteria. Clarythromycin was the most active against Mycoplasma species.

Conclusions: Pregnant women with vaginal complaints revealed various positive microbiology results. Such cases may require specific medication. Routine culture of vaginal and cervical samples should be performed on all pregnant women during prenatal visits.
\end{abstract}

Key words: vaginitis; vaginosis; pregnant women; antimicrobial susceptibility; Sudan

J Infect Dev Ctries 2014; 8(4):490-497. doi:10.3855/jidc.3197

(Received 30 November 2012 - Accepted 06 May 2013)

Copyright (C) 2014Abdelaziz et al. This is an open-access article distributed under the Creative Commons Attribution License, which permits unrestricted use, distribution, and reproduction in any medium, provided the original work is properly cited.

\section{Introduction}

Microbial infections of the vagina (vaginosis and vaginitis) among pregnant women are serious problems because they can lead to serious medical complications such as preterm labor, amniotic fluid infection, premature rupture of the fetal membranes, and low birth weight of the neonate [1], leading to high prenatal mortality [2]. However, proper identification and treatment will reduce the risk of preterm birth and its consequences [3].

The vagina could be infected by a variety of pathogens including bacteria, fungi, viruses, and parasites [1,2]. Bacterial vaginosis (BV) is the most frequent vaginal infection, characterized by the replacement of Lactobacillus species of normal vaginal flora by the excessive growth of a mixture of microorganisms including Gardnerella vaginalis,
Bacteroides species, genital mycoplasma, and fastidious anaerobic bacteria [4].

Vaginal complaints such as BV, candidiasis, trichomoniasis, and Chlamydia trachomatis infections are common among women of reproductive age, with high incidences during pregnancy $[5,6]$. For unknown reasons, they are more prevalent in women in subSaharan Africa and other low-income countries than in women in developed countries [4], affecting up to $55 \%$ of women in some studies [4]. In Sudan, there is little data about vaginal infections in pregnant women $[7,8,9]$. BV has been found in $17.2 \%$ of subjects, candidiasis in $10.1 \%$, trichomoniasis in $7.7 \%$, gonorrhoeae in $1.2 \%, \mathrm{HIV}$ in $1.2 \%$, and syphilis in $0.9 \%$ of Sudanese women examined in the El Obeid region [8].

Vaginal conditions could be diagnosed using known Amsel's clinical criteria including vaginal 
discharge appearance, $\mathrm{pH}$ measurement, whiff test, and clue cell on microscopy [10]; however, these requirements alone cannot identify the cause of vaginal illness [11]. According to the Centers for Disease Control and Prevention, there are various guidelines can be used for the diagnosis of vaginal infections, such as wet mount microscopy, direct Gram staining, potassium hydroxide preparation, routine culture, Papanicolaou smear, or DNA probes [12]. This study aimed to investigate the causative agents of vaginal infections and antimicrobial susceptibilities of the isolates from pregnant women at Omdurman Maternity Hospital in Khartoum, Sudan, using different laboratory techniques.

\section{Methodology}

Study design

This was a cross-sectional study carried out at Omdurman Maternity Hospital in Khartoum, Sudan, between August and December 2008. Pregnant women $(n=200)$ between 17 and 47 years of age suspected of having symptomatic and asymptomatic vaginal infections were enrolled during routine prenatal visits to the gynecology and obstetrics clinic. Patients' data, which included age, location, previous history of abortions, last menstrual period, and clinical signs and symptoms, were obtained from patients' referral files and laboratory request forms. Pregnant women in the third and second trimester of gestation were included in the study, while those in the first trimester were excluded to avoid abortion cases. The study was approved by the Research Council Board of the Faculty of Medical Laboratory Science, Khartoum University.

\section{Sample collection and transportation}

Vaginal and cervical swabs samples were obtained from each subject using the standard sampling technique for microbiological investigation described by Onderdonk et al. [13]. Three high vaginal swabs were collected from each patient by a gynecologist and placed into Amies transport medium. One cervical swab was taken to prepare the smear on a sterile glass slide for the detection of C.trachomatis using the immunoflourescence technique, and the remaining swab sample was placed into a mycoplasma transport medium R1 for transportation. Once the samples were obtained, they were transported within three hours to the Microbiology Laboratory Department at Faculty of Medical Laboratory Sciences, University of Khartoum.
Sample processing

After the samples were submitted to the microbiology laboratory, they were processed immediately for possible isolation and identification of pathogenic microorganisms in accordance with standard laboratory methods $[14,15]$.

Of the three high vaginal swabs obtained from each patient, one swab sample was inoculated immediately onto blood agar (Oxoid, Basingstoke, UK), MacConkey agar (Oxoid, Basingstoke, UK) plates, Sabouraud agar (Oxoid, Basingstoke, UK) and incubated aerobically at $37^{\circ} \mathrm{C}$ for 48 hours, while the inoculated chocolate blood agar plate was incubated aerobically with $20 \% \mathrm{CO}_{2}$ moist atmosphere. The second sample was placed into a sterile universal container containing $10 \mathrm{~mL}$ of freshly prepared cooked meat medium for anaerobic isolation. The third sample was used for direct microscopic examination of Trichomonas vaginalis. The cervical samples were processed for the detection of $C$. trachomatis and Mycoplasma species.

\section{Diagnosis of vaginosis}

BV was diagnosed based on Amsel's clinical criteria [10] and standard microbiological techniques $[14,15]$.

In Amsel's methods, three of the four criteria should be recorded: a vaginal $\mathrm{pH}$ of greater than $\mathrm{pH}$ 4.5; the presence of clue cells in the vaginal fluid; a milky, homogeneous vaginal discharge; and the release of a fishy odor after the addition of $10 \%$ potassium hydroxide to the vaginal fluid [10].

\section{Microscopic examination}

A wet preparation of vaginal swab samples were examined microscopically for the presence of yeast cells, clue cells, and T. vaginalis [15]. Direct Gram stain smears were then prepared for diagnosis of BV by the Nugent scoring system [16]. The Gram smear was examined for the following morphotypes: large Gram-positive rods (Lactobacillus morphotypes), small Gram-variable rods (Gardnerella vaginalis morphotypes), small Gram-negative rods (Bacteroides species morphotypes), curved Gram-variable rods (Mobiluncus species morphotypes), and Gram-positive cocci. Increased numbers of Gram-positive cocci are not part of the pattern of the normal vaginal flora. A score of zero to three was considered to be normal, and a score of four to ten was defined as BV (Table 1). In case of Neisseria gonorrhoeae, intracellular Gramnegative diplococci were examined [15]. 
Table 1: Scoring system (0-10) for the Gram-stained vaginal smears*

\begin{tabular}{cccc}
$\begin{array}{c}\text { Curved Gram-negative variable } \\
\text { rods }\end{array}$ & $\begin{array}{c}\text { Gardnerella and } \\
\text { Bacteroidesspecies } \\
\text { morphotypes }\end{array}$ & Lactobacillusmorphotypes & Score \\
\hline 0 & 0 & $4+$ & $3+$ \\
$1+$ or $2+$ & $1+$ & $2+$ & 1 \\
$3+$ or $4+$ & $2+$ & $1+$ & 2 \\
& $3+$ & 0 & 3 \\
\hline
\end{tabular}

$1+\leq 1 / 1000 \times$ field; $2+=1-5 / 1000 \times$ field; $3+=6-30 / 1000 \times$ field; $4+\geq 30 / 1000 \times$ field

*adapted from Nugent et al. $(15=1991)$

\section{Identification of genital microorganisms}

Isolated bacteria were identified by conventional methods [14,15] including Gram stain, colonial morphology, germ tube test, motility, and biochemical tests such as catalase, coagulase, DNAse, Indole, lactose fermentation, citrate utilization, urease, Kligler iron, oxidase, sugar fermentation, and automated system (Vitek II, bio-Mérieux, Marcy l'étoile, France). The identification of the Lancefield antigen was done using the Streptococcal Grouping Kit (Oxoid, Basingstoke, UK).

\section{Antimicrobial susceptibility testing}

Antimicrobial susceptibility testing of isolates was performed on Mueller-Hinton agar plate (HiMedia, Mumbai, India) by the Kirby-Bauer disk diffusion method following the National Committee for Clinical Laboratory Standards Interpretative (CLSI) criteria [17]. The antimicrobial agents tested were amoxicillinclavulanic acid $(30 \mu \mathrm{g})$, penicillin $\mathrm{G}(10 \mu \mathrm{g})$, cefotaxime $(30 \mu \mathrm{g})$, ceftazidime $(30 \mu \mathrm{g})$, ceftriaxone (30 $\mu \mathrm{g})$, cefuroxime $(30 \mu \mathrm{g})$, cephalothin, cotrimoxazole $(25 \mu \mathrm{g})$, ciprofloxacin $(5 \mu \mathrm{g})$, gentamicin (10 $\mu \mathrm{g})$, imipenem $(10 \mu \mathrm{g})$, kanamycin $(30 \mu \mathrm{g})$, metronidazole $(5 \mu \mathrm{g})$, piperacillin $(100 \mu \mathrm{g})$, tetracycline $(30 \mu \mathrm{g})$, and vancomycin $(30 \mu \mathrm{g})$ (Oxoid, Basingstoke, UK).Standardized inoculum adjusted to $0.5 \mathrm{McFarland}$ standard turbidity of each isolate was inoculated onto Mueller-Hinton agar plates using a sterile cotton swab by streaking the swab over the entire sterile agar surface three times. Sterile forceps were used to place the appropriate antibiotic disks on the inoculated plate. The plates were incubated aerobically at $37^{\circ} \mathrm{C}$ overnight, and then tests were read. The control strain was tested each time when susceptibility testing was performed. Test results were only validated in the cases where inhibition zone diameters of the control strains were within performance ranges in accordance with CLSI guidelines [17].
Identification and susceptibility of Mycoplasma species

Mycoplasma IST 2 strip diagnostic kit (bioMerieux, Marcy 1'Etoile, France) was used for identification and determination of antimicrobial susceptibility of Ureaplasma urealyticum and Mycoplasma hominis. The test kit was used according to the manufacturer's instructions. Cervical swab samples were placed into R1 transport medium and mixed; $3 \mathrm{~mL}$ of $\mathrm{R} 1$ was then transferred to the mycoplasmaR2 vial to reconstitute the lyophilized growth medium. ThemycoplasmaIST 2 strip containing 22 test wells was inoculated with the reconstituted medium (mycoplasmaR1 + mycoplasma broth R2). An adjusted $55 \mu \mathrm{L}$ volume of the medium was dispensed into each of the 22 test wells, then two drops of mineral oil were added on top of each well, and the lid was placed on the strip and incubated together with the remaining inoculum in the mycoplasmaR2 vial at $37^{\circ} \mathrm{C}$. The results were interpreted after 24 and 48 hours of incubation. The strip containing 22 tests was evaluated after being divided into three sections: well 1 as growth control, wells 2 to 5 identified the presence of $M$. hominis and $U$. urealyticum and determined growth count (equals to or higher than the threshold set at $10^{4}$ colonyforming units), and the remaining wells, 6 to 22, were used to test the susceptibility of the identified strains against nine antibiotics (in two different concentrations) including doxycycline (4 and $8 \mathrm{mg} / \mathrm{L}$ ), josamycin (2 and $8 \mathrm{mg} / \mathrm{L})$, ofloxacin ( 1 and $4 \mathrm{mg} / \mathrm{L}$ ), erythromycin (1 and $4 \mathrm{mg} / \mathrm{L}$ ), tetracycline (4 and 8 $\mathrm{mg} / \mathrm{L}$ ), ciprofloxacin (1 and $2 \mathrm{mg} / \mathrm{L}$ ), azithromycin (0.12 and $4 \mathrm{mg} / \mathrm{L})$, clarythromycin (1 and $4 \mathrm{mg} / \mathrm{L})$, and pristinamycin $(2 \mathrm{mg} / \mathrm{L})$.

Direct fluorescence test for the detection of Chlamydia trachomatis

Chlamydia DFA kit (bioMérieux, Marcy l'étoile, France) was used to detect $C$. trachomatis serovars A, $\mathrm{B}, \mathrm{Ba}, \mathrm{C}, \mathrm{D}, \mathrm{E}, \mathrm{F}, \mathrm{G}, \mathrm{H}, \mathrm{I}, \mathrm{J}, \mathrm{K}, \mathrm{LGV} 1, \mathrm{LGV} 2$, and 
LGV3. The cervical swab smear was prepared on a sterile class slide. The smear was allowed to air dry, then fixed in methanol for 5 minutes. It was then drained and air dried and stained following the manufacturer's instructions. Briefly, a total volume of $25 \mu \mathrm{L}$ of chlamydial DFA reagent was dispensed onto the fixed smear and the positive control; the slides were then incubated in a moist chamber for 30 minutes in the dark, then rinsed gently in a bath of phosphate buffer saline for approximately 1 minute. The excess moisture around the well was removed using absorbent tissue, one drop of mounting fluid was added to the well, and a glass cover was then placed gently to avoid air bubbles. The entire sample was then scanned using a fluorescence microscope after adding oil immersion at $\times 600$ to $\times 1000$ magnification.

Intracellular elementary bodies were detected within the cells as bright, apple-green fluorescent pinpoint, smooth-edged disk-shaped bodies against a red background of counterstained cells and were seen extracellularly as a bright apple-green fluorescence against a black background. Inclusion bodies were also seen. A fixed smear free of any chlamydial bodies but containing cells indicated negative results.

\section{Statistical analysis}

Descriptive analysis and comparison of proportions was performed using SPSS statistical software version 12.0.1 (SPSS Inc., Chicago, IL, USA). All $\mathrm{p}$ values $<0.05$ were considered statistically significant.

\section{Results}

Of the 200 pregnant women enrolled, $176(88 \%)$ were found to be positive for all types of vaginal and cervical infections (BV, candidiasis, C.trachomatis infection, gonorrhoeae, and trichomoniasis). Out of the 176 infected women, $71.6 \%(126 / 176)$ were in the third trimester of gestation, whereas $28.4 \%$ (50/176) were in the second trimester. Of these, the most common infected age groups were the 21-30 group, followed by the 31-40 group (Figure 1). Of the 176 vaginal infection cases, the causative agents varied from single infection caused by one type of microorganism to polymicrobial infections; a total number of 434 significant microorganisms were identified by laboratory methods. The majority of subjects were infected by three organisms $(35.2 \%$, $62 / 176)$ and two organisms $(31.1 \%, 60 / 176)$, followed by one organism $(18.2 \%, 32 / 176)$ and more than three organisms $(12.5 \%, 22 / 176)$.
Figure 1. Frequency of vaginal infections by age group of pregnant women $(n=176)$ at Omdurman Maternity Hospital, Khartoum State, Sudan

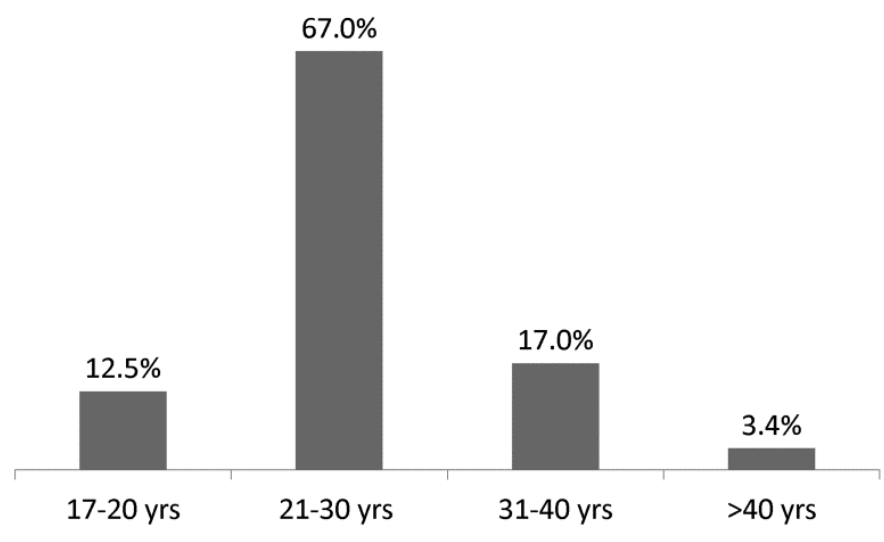

Figure 2. Types and proportions of microorganisms $(n=434)^{*}$ recovered from 176 pregnant women with vaginal infections at Omdurman Maternity Hospital, Khartoum, Sudan (*more than one organism could be isolated from one patient)

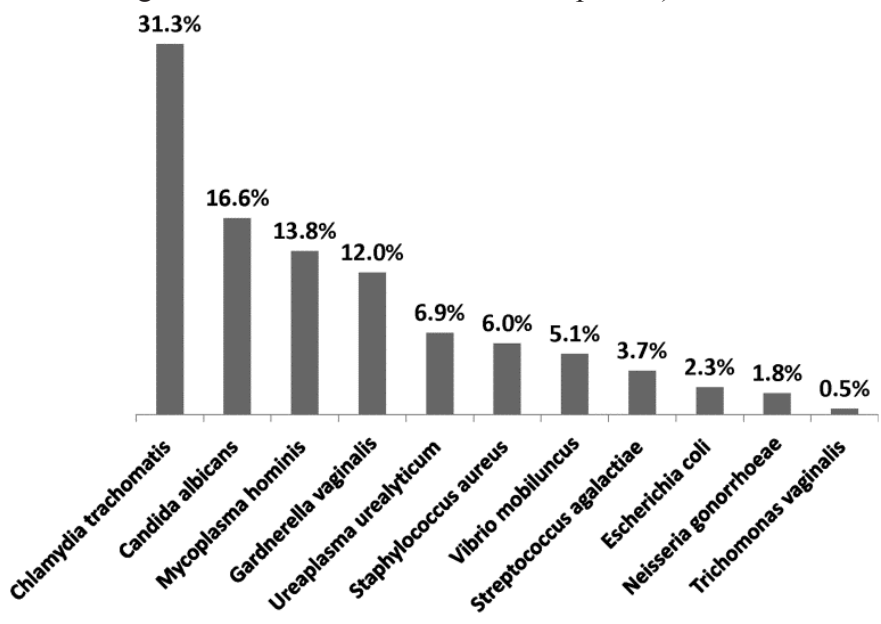

Prevalence rates of various types of infections

Among the vaginal infections detected, BV was the most prevalent, found in $49.8 \%$ of samples, followed by $C$. trachomatis infection (31.3\%) and candidiasis $(16.6 \%)$, with low frequencies of gonorrhoeae (1.8\%) and trichomoniasis (0.5\%) infections.

\section{Etiological agents of bacterial vaginosis}

Figure 2 illustrates the types and proportions of microorganisms $(n=434)$ recovered from the 176 pregnant women with vaginal infections at Omdurman Maternity Hospital, Khartoum. As shown in Figure 2, the most common BV microorganisms were $M$. hominis $(\mathrm{n}=60,13.8 \%)$, followed by G.vaginalis $(\mathrm{n}=$ $52,12 \%)$, Ureaplasma urealyticum $(\mathrm{n}=30,6.9 \%)$, 
Staphylococcus aureus ( $=26,6 \%)$, Vibrio mobiluncus $(\mathrm{n}=22,5.1 \%)$, Streptococcus agalactiae $(\mathrm{n}=16,3.7 \%)$, and Escherichia coli $(\mathrm{n}=10,2.3 \%)$.

Distribution of chlamydial infections according to history of abortion

The distribution of C. trachomatis infections in pregnant women at Omdurman Maternity Hospital according to their history of abortion is shown in Figure 3. No significant association $(p=0.7)$ was found between history of abortion and the presence of C.trachomatis infections in the studied group.

\section{Antibiotic susceptibility patterns of the bacterial isolates}

Table 2 shows the antibiotic susceptibility of different bacterial isolates from pregnant women with vaginosis cases at Omdurman Maternity Hospital. Gentamicin was the most active antibiotic against both Gram-positive and Gram-negative bacteria. Vancomycin was the most active antibiotic against Gram-positive bacteria, followed by amoxicillinclavulanic acid. Imipenem was the most active antibiotic against anaerobic bacteria.

The most common active antibiotics against Mycoplasma species were clarythromycin and tetracycline. In general, $M$. hominis were more susceptible to the tested antibiotics than $U$. urealyticum (Table 3).

\section{Discussion}

Pregnant women have a twofold increase in the prevalence of vaginal microorganisms colonization compared to non-pregnant women. Increased levels of circulating estrogens and deposition of glycogen and other substrates in the vagina during pregnancy [18] influence this association. In the present study, pregnant women demonstrated various types of vaginal infections present in either one or more than one microorganism per case. Nevertheless, BV represented $49.8 \%$ of vaginal infections. This finding is similar to findings other studies in various African countries such as the $32 \%$ rate of BV recorded among women in Ethiopia [19], 47.7\% in Uganda [20], and $62.6 \%$ in Tanzania [21]. Such large ratios of pregnant women with positive culture or vaginosis might necessitate medical treatments and indicate the high prevalence and variations in the causal agents associated with vaginal infections. This outcome cast doubt on whether diagnosis and management of this condition should be revised in countries such as Sudan. This is because BV increases the risk of
Figure 3. Association between Chlamydia trachomatis infections and numbers of abortions in pregnant women

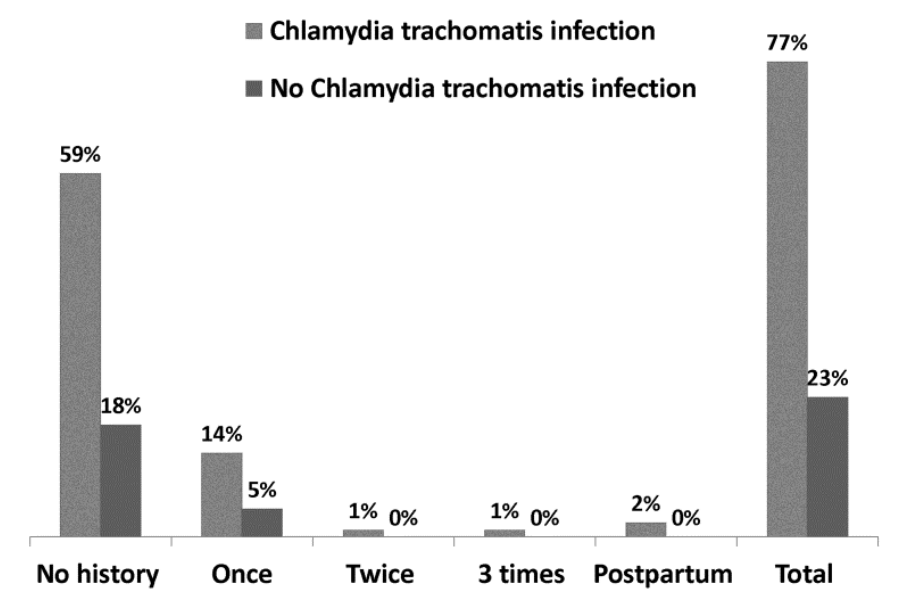

sexually transmitted infection, including HIV $[4,22,23]$. Failure to detect it could have serious effects on women's health.

According to the meta-analysis carried out by Leitich et al. [24,25], pregnant women with BV have an over twofold greater risk of preterm delivery than women without BV (odds ratio: 2.16; 95\% CI: 1.563.00). This risk was shown to be even greater among women in whom BV was diagnosed early in pregnancy. Among women undergoing preterm labor, BV doubles the risk of delivering before 37 weeks of gestation (odds ratio: 2.38; 95\% CI: 1.02-5.58) [25]. In addition, $\mathrm{BV}$ increases the risk of late miscarriage and maternal infection postpartum [25]. While BV has been found to be associated with preterm birth, no link has been found with neonatal infection or perinatal mortality.

Genital mycoplasma, including $M$. hominis and $M$. Ureaplasma spp., are suspected to contribute to a number of pathological conditions such as preterm birth, premature birth, low birth weight, and perinatal morbidity and mortality [26]. In this study, the higher frequency of infection among Mycoplasma species isolates was due to $M$. hominis $(13.8 \%)$ than to $U$. urealyticum (6.9\%) infection. M. hominis accounted for $35 \%$ of the vaginosis cases in Nigerian women and it was regarded as the most common isolate [27]. The present study can be compared with a study carried out in Poland [28], which found that U. urealyticum and M. hominis infections accounted for $29.5 \%$ and $3.7 \%$ of vaginosis cases, respectively. It is obvious that there are significant differences between our results and results from Nigeria and Poland. 


\begin{tabular}{|c|c|c|c|c|c|c|c|c|c|c|c|c|c|c|c|c|c|}
\hline \multirow[b]{2}{*}{ Microorganism } & \multirow[b]{2}{*}{$\begin{array}{c}\text { Number of } \\
\text { isolates }\end{array}$} & \multicolumn{16}{|c|}{ Antimicrobial agent } \\
\hline & & 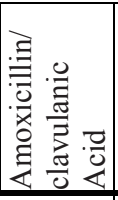 & 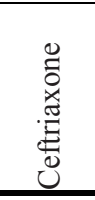 & 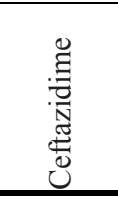 & 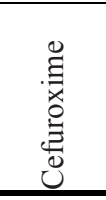 & 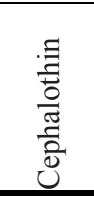 & 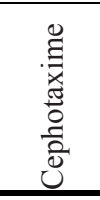 & 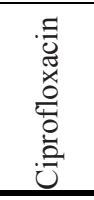 & 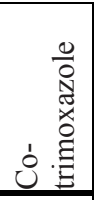 & 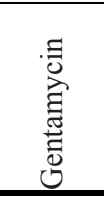 & 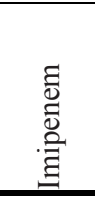 & 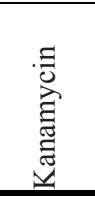 & 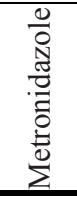 & $\begin{array}{l}. \Xi \\
. \bar{\Xi} \\
. \overline{0} \\
. \\
\end{array}$ & 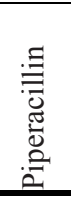 & 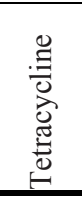 & 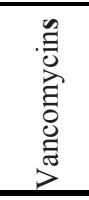 \\
\hline Gardnerellavaginalis & 52 & $100 \%$ & $100 \%$ & $8076 \%$ & $8 \%$ & $4 \%$ & $23 \%$ & - & $31 \%$ & $100 \%$ & $96 \%$ & $4 \%$ & $0 \%$ & $0 \%$ & $4 \%$ & - & $100 \%$ \\
\hline Streptococcus agalactiae & 16 & $100 \%$ & $25 \%$ & $25 \%$ & - & - & - & - & $9 \%$ & $100 \%$ & - & $100 \%$ & - & $100 \%$ & - & $75 \%$ & $100 \%$ \\
\hline Neisseria gonorrhoeae & 8 & - & $100 \%$ & $75 \%$ & $100 \%$ & $0 \%$ & $100 \%$ & $100 \%$ & $75 \%$ & $100 \%$ & - & $0 \%$ & $0 \%$ & $0 \%$ & $0 \%$ & - & - \\
\hline Escherichia coli & 10 & $80 \%$ & $20 \%$ & $60 \%$ & - & - & - & $100 \%$ & $0 \%$ & $80 \%$ & - & - & - & $0 \%$ & - & $60 \%$ & - \\
\hline Staphylococcus aureus & 26 & $100 \%$ & - & $92 \%$ & - & - & - & - & $0 \%$ & $100 \%$ & $92 \%$ & - & - & $0 \%$ & - & - & $92 \%$ \\
\hline Vibrio mobiluncus & 22 & - & $100 \%$ & $100 \%$ & - & $100 \%$ & $100 \%$ & $82 \%$ & $91 \%$ & $100 \%$ & $100 \%$ & - & $64 \%$ & - & - & - & $100 \%$ \\
\hline
\end{tabular}

Table 3: Antibiotic susceptibility patterns of the Mycoplasma species isolated from vaginosis cases at Omdurman Maternity Hospital, Khartoum, Sudan to 9 various antimicrobial agents

\begin{tabular}{|c|c|c|c|c|c|c|c|c|c|c|}
\hline \multirow[b]{2}{*}{ Species } & \multirow[b]{2}{*}{$\begin{array}{l}\begin{array}{l}\text { Number of } \\
\text { strains }\end{array} \\
\end{array}$} & \multicolumn{9}{|c|}{ Antimicrobial agent } \\
\hline & & 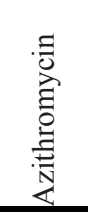 & 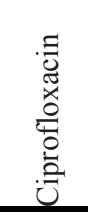 & 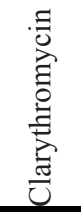 & 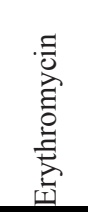 & 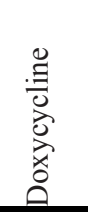 & 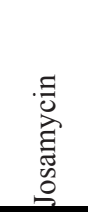 & 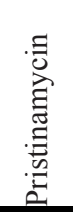 & 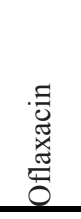 & 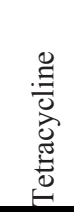 \\
\hline Mycoplasma hominis & 60 & $77 \%$ & $73 \%$ & $93 \%$ & $77 \%$ & $60 \%$ & $70 \%$ & $53 \%$ & $45 \%$ & $77 \%$ \\
\hline Ureaplasmaurealyticum & 30 & $87 \%$ & $67 \%$ & $87 \%$ & $73 \%$ & $67 \%$ & $53 \%$ & $53 \%$ & $47 \%$ & $80 \%$ \\
\hline
\end{tabular}


In the present study, significant proportions of vaginal infections were reported due to vaginal candidiasis and trichomoniasis. In comparison to a previous study conducted on a similar population in Sudan, our study reported higher rates $(16.6 \%)$ of candidiasis than the $10.1 \%$ reported by Kafi et al. [8]. In contrast, these authors recorded $7.7 \%$ of genital infections due trichomoniasis, which was higher than the $0.5 \%$ in our study. In another study carried out in Khartoum, the prevalence of $C$. trachomatis, $T$. vaginalis, $N$. gonorrhoeae, and candidiasis among pregnant women attending an antenatal clinic was reported to be $7.3 \%$ in patients suffering multiple infections [7]. The variation of these isolation rates may be due to socio-economic status and immunity of patients, or environmental, nutritional, or cultural factors.

In the present study, $C$. trachomatis was the most prevalent microorganism (31.3\%). This result is higher than the 3.9\% observed in Jordan [29] and the 8\% reported in pregnant woman in Botswana [30].In developing countries, including Sudan, diagnosis of cervical infections namely due to $C$. trachomatisis limited to the syndromic approach of relying on the appearance of vaginal discharge [31]. Due to the high prevalence of $C$. trachomatis infections in this study, routine diagnostic techniques such as the direct fluorescence test or polymerase chain reaction are needed in our hospitals. Though $C$. trachomatis infections can lead to spontaneous abortion in early pregnancy, the study did not demonstrate a significant association between previous abortions among studied populations and the presence of $C$. trachomatis. However, our clinical specimens were obtained from pregnant women in the second and third trimesters to avoid risk of abortion.

$\mathrm{BV}$ is a polymicrobial infection and asymptomatic carriage $(G$. vaginalis) is found in up to $70 \%$ of women. These factors render routine culture and antibiotic sensitivity testing requests inappropriate. However, a culture is appropriate to exclude or to confirm notable agents, namely Trichomonas species, C. trachomatis, and $N$. gonorrhoeae [32,33]. The standard treatment for BV, vulvovaginal candidiasis, and trichomoniasis is oral metronidazole at a dosage of $500 \mathrm{mg}$ twice daily for seven days.

The present study demonstrated that $64 \%$ of the isolates of Vibrio mobiluncus were sensitive to metronidazole, whereas $G$. vaginalis and $N$. gonorrhoeae isolates were resistant.One of the limitations of this study was gaps in the in vitroantimicrobial testing for some isolated organisms
(Table 2), but a good number of antimicrobial agents were tested against Mycoplasma species. The antimicrobial susceptibility testing of isolated bacteria showed that clarythromycin was active against both $M$. hominis and U. urealyticum. Gentamicin was the most active antibiotic against both Gram-positive and Gram-negative bacteria. Vancomycin was active against Gram-positive bacteria. Ciprofloxacin was the most active drug against Gram-negative, and imipenem was most active against anaerobic organisms. Shopova et al. [34] reported G. vaginalis as the main microorganisms related to recurrent $\mathrm{BV}$; it was sensitive in $34 \%$ of cases to metronidazole and in $82 \%$ of cases to clindamycin. Such results show that the general administration of metronidazole is a standard treatment, regardless of its in vitro results.

\section{Conclusions}

In conclusion, this study revealed the polymicrobial nature and high prevalence of vaginal complaints such as BV (49.8\%) and C. trachomatis infections among pregnant women. Such cases may require specific medical treatment. Routine vaginal and cervical swab sample cultures should be performed on all pregnant women during prenatal visits, especially during the second and third trimesters. Generally, the administration of metronidazole as a standard treatment against vaginal infections is not in line with the in vitro antimicrobial sensitivity results.

\section{Acknowledgements}

The authors are grateful to Saher Mohammed, Esraa Omer and Naglaa Ahmed and Dr. Murwan Ibrahim Omer and all the staff members in Omdurman Maternity Hospital (Al Dayat) and the Department of Medical Microbiology at Faculty of Medical Laboratory Sciences, University of Khartoum, for their help during the period of sample collection and processing.

\section{References}

1. Giraldo PC, Araújo ED, Junior JE, do Amaral RL, Passos MR, Gonçalves AK (2012) The prevalence of urogenital infections in pregnant women experiencing preterm and fullterm labor. Infect Dis Obstet Gynecol 2012: 878241.

2. Dover SE, Aroutcheva AA, Faro S, Chikindas ML (2008) Natural antimicrobials and their role in vaginal health: a short review. Int J Probiotics 3: 219-230.

3. McDonald H, Brocklehurst P, Parsons J (2005) Antibiotics for treating bacterial vaginosis in pregnancy. Cochrane Database Syst Rev 25: CD000262.

4. Cohen CR, Lingappa JR, Baeten JM, Ngayo MO, Spiegel CA, Hong T, Donnell D, Celum C, Kapiga S, Delany S, Bukusi EA (2012) Bacterial vaginosis associated with increased risk of female-to-male HIV-1 transmission: a 
prospective cohort analysis among African couples. PLoS Med 9: e1001251.

5. Einarson A, Koren G (2002) Bacterial vaginosis during pregnancy. Should we screen for and treat it? Can Fam Physician 48: 877-878.

6. Tolosa JE, Chaithongwongwatthana S, Daly S, Maw WW, Gaitán H, Lumbiganon P, Festin M, Chipato T, Sauvarin J, Goldenberg RL, Andrews WW, Whitney C (2006) The International Infections in Pregnancy (IIP) study: variations in the prevalence of bacterial vaginosis and distribution of morphotypes in vaginal smears among pregnant women. Am J Obstet Gynecol 195: 1198-1204.

7. Ortashi OM, El Khidir I, Herieka E (2004) Prevalence of HIV, syphilis, Chlamydia trachomatis, Neisseria gonorrhoea, Trichomonas vaginalis and candidiasis among pregnant women attending an antenatal clinic in Khartoum, Sudan. J Obstet Gynaecol 24: 513-515.

8. Kafi SK, Mohamed AO, Musa HA (2000) Prevalence of sexually transmitted diseases (STD) among women in a suburban Sudanese community. Ups J Med Sci 105: 249-253.

9. Kafi SK, Musa HA (2012) Bacterial Vaginosis. Sudan J Med Sci 7: 49-52.

10. Amsel R, Totten PA, Spiegel CA, Chen KCS, Eschenbach DA, Holmes KK (1983) Nonspecific vaginitis: diagnostic criteria and epidemiologic associations. Am J Med 74: 14-22.

11. Anderson MR, Klink K, Cohrssen A (2004). Evaluation of vaginal complaints. JAMA 291: 1368-1379.

12. Centers for Disease Control and Prevention (2006) Diseases characterized by vaginal discharge. Section of Sexually transmitted diseases treatment guidelines. Available at: www.cdc.gov/mmwr/preview/mmwrhtml/rr5511a1.htm. Accessed 4 August 2006.

13. Onderdonk AB, Lee ML, Lieberman E, Delaney ML, Tuomala RE (2003) Quantitative microbiologic models for preterm delivery. J Clin Microbiol 41: 1073-1079.

14. Farmer, J.J.III., (1995) Enterobacteriaceae: Introduction and identification. In: Murry PR, Paron EJ, Pxaller MA, Tenover $\mathrm{SC}$, Yolken RH, editors. Manual of Clinical Microbiology, $6^{\text {th }}$ edition. Washington DC: ASM Press. 438-449.

15. Cheesbrough M (2000) Examination of urogenital specimens. In District Laboratory Practice in Tropical Countries, Volume 2. Cambridge University Press: Cambridge. 93-94.

16. Nugent RP, Krohn MA, Hillier SL (1991) Reliability of diagnosing bacterial vaginosis is improved by a standardized method of gram stain interpretation. J Clin Microbiol 29: $297-$ 301.

17. Clinical and Laboratory Standards Institute (2007) Performance standards for antimicrobial susceptibility testing; 17 th informational supplement M100-S17. Clinical and Laboratory Standards Institute, Wayne, PA.

18. Sobel JD (2007) Vulvovaginal candidosis. Lancet 369: 19611971.

19. Ayenalem S, Yusuf L, Ashenafi M (2010) Lactic acid bacterial vaginosis among outpatients in Addis Ababa. Ethiopian J Hlth Dev 24: 198-204.

20. Tann CJ, Mpairwe H, Morison L, Nassimu K, Hughes P, Omara M, Mabey D, Muwanga M, Grosskurth H, Elliott AM (2006) Lack of effectiveness of syndromic management in targeting vaginal infections in pregnancy in Entebbe, Uganda. Sex Transm Infect 82: 285-289.

21. Baisley K, Changalucha J, Weiss HA, Mugeye K, Everett D, Hambleton I, Hay P, Ross D, Tanton C, Chirwa T, Hayes R, Watson-Jones D (2009) Bacterial vaginosis in female facility workers in north-western Tanzania: prevalence and risk factors. Sex Transm Infect 85: 370-375.

22. Cohen CR, Duerr A, Pruithithada N, Rugpao S, Hillier S, Garcia P, Nelson K (1995) Bacterial vaginosis and HIV seroprevalence among female commercial sex workers in Chiang Mai, Thailand. AIDS 9: 1093-1097.

23. Sewankambo N, Gray RH, Wawer MJ, Paxton L, McNaim D, Wabwire-Mangen F, Serwadda D, Li C, Kiwanuka N, Hillier SL, Rabe L, Gaydos CA, Quinn TC, Konde-Lule J (1997) HIV-1 infection associated with abnormal vaginal flora morphology and bacterial vaginosis. Lancet 350: 546-550.

24. Leitich H, Bodner-Adler B, Brunbauer M, Kaider A, Egarter C, Husslein P (2003) Bacterial vaginosis as a risk factor for preterm delivery: a meta-analysis. Am J Obstet Gynecol 189: 139-141.

25. Leitich H, Kiss H (2007) Asymptomatic bacterial vaginosis and intermediate flora as risk factors for adverse pregnancy outcome. Best Pract Res Clin Obstet Gynaecol 21: 375-390.

26. Kataoka S, Yamada T, Chou K, Nishida R, Morikawa M, Minami M, Yamada H, Sakuragi N, Minakami HJ (2006) Association between preterm birth and vaginal colonization by mycoplasmas in early pregnancy. Clin Microbiol 44: 5155.

27. Anukam KC and Reid G (2007) Organisms associated with bacterial vaginosis in Nigerian women as determined by PCR-DGGE and 16S rRNA gene sequence. Afr Hlth Sci 7: 68-72.

28. Zdrodowska-Stefanow B, Kłosowska WM, OstaszewskaPuchalska I, Bułhak-Kozioł V, Kotowicz B (2006) Ureaplasma urealyticum and Mycoplasma hominis infection in women with urogenital diseases. Adv Med Sci 51: 250253.

29. Al-Ramahi M, Mahafzah A, Saleh S, Fram K (2008) Prevalence of Chlamydia trachomatis infection in infertile women at a university hospital in Jordan. East Mediterr Health J 14: 1148-1154.

30. Romoren M, Sundby J, Velauthapillai M, Rahman M, Klouman E, Hjortdahl P (2007) Chlamydia and gonorrhoea in pregnant Batswana women: time to discard the syndromic approach? BMC Infect Dis 7: 27.

31. Romoren M, Velauthapillai M, Rahman M, Sundby J, Klouman E, Hjortdahl P (2007) Trichomoniasis and bacterial vaginosis in pregnancy: inadequately managed with the syndromic approach. Bull World Health Organ 85: 297-304.

32. Leppäluoto PA (2011) Bacterial vaginosis: what is physiological in vaginal bacteriology? An update and opinion. Acta Obstet Gynecol Scand 90: 1302-1306.

33. Nelson A, De Soyza A, Perry JD, Sutcliffe IC, Cummings SP (2012) Polymicrobial challenges to Koch's postulates: Ecological lessons from the bacterial vaginosis and cystic fibrosis microbiomes. Innate Immun 18: 774-783.

34. Shopova E, Nikolov A, Dimitrov A (2011) Susceptibility to antibiotics of microorganisms related with recurrent bacterial vaginosis. Akush Ginekol (Sofiia) 50: 20-21.

\section{Corresponding author}

Dr. Mutasim E. Ibrahim

Faculty of Medical Laboratory Sciences

University of Khartoum

P.O. Box 11081, Khartoum, Sudan

Email: mutasimhadi87@hotmail.com

Conflict of interests: No conflict of interests is declared. 